\title{
NF1 Mutation Analysis Was Not Performed
}

National Cancer Institute

\section{Source}

National Cancer Institute. NF1 Mutation Analysis Was Not Performed. NCI Thesaurus.

Code C160427.

An indication that NF1 mutation analysis was not performed during the study. 